\title{
Design and tension control of double drum Winch system for deep-sea exploration equipment
}

\author{
Muhammad Shahid Shafi ${ }^{a}$, Jianhui Lu ${ }^{b}$, Zhenpeng Song ${ }^{c}$ and Yingqun Fu ${ }^{d}$ \\ College of Engineering, Ocean University of China, Qingdao 266100, China \\ am.shahidshafi02@gmail.com, 'bujianhui@ouc.edu.cn, 'szpeng91@sina.com, \\ dyingqunfu@163.com
}

Keywords: Deep-sea engineering, Traction Winch, Double Drum Winch, Tension Control, Fuzzy PID.

\begin{abstract}
This paper puts forward the structure scheme of dual winch with separation of storage and a traction mechanism. In view of the problems about the existing cable arrangement of single drum winch retracting long deep-sea detector cable where the tension is uneven. Whereas the traction winch with double drum structure, composed of two parallel groove drums, two drums driving at the same time. The cable winding in order on two drums. According to the deep water monitoring specific tasks, for different parts of the system to carry out the design and calculation, the scheme satisfies the requirements of deep water monitoring, achieves the design aim to control tension and extend the service life of the cable..
\end{abstract}

\section{Introduction}

Underwater detector as a kind of important means, in the process of human exploration, research and development of marine resources is an important task. In order to realize the real-time detection, the detector and the support ship connected through a cable, obtain the power and transmission of information from the mothership. The hoisting cable is usually the detector, detector cable winch is the important equipment in water. Working in shallow water of draw work generally use the single drum structure, that bears the cable lifting and storage work. With the detector operating depth deepening, cable length become longer, in the process of retraction detectors, will appear the following changes:

Detector goes into the water, the main load on winch is the weight of the cable and detector in the water, cable weight and water depth is proportional, with increasing operating depth, cable weight also continue to increase, and will be more than the weight of the detector in the water, has gradually become the main load on winch.

Due to the increase of the length of the cable, at the same time limited by the guide wheel angle, winch length cannot be too large, resulting in the increase of cable layers on winch drum, resulting in increase of winch rotational inertia, the required driving torque is greatly increased.

Cable tension on the winch drum causes large change between the layers. When lifting the bulky equipment in front of the detector effluent minimum tension, and in the detector effluent buoyancy disappears weight suddenly increases, resulting in the outermost layer of the cable winch tension of the water is much larger than before winding tension, which may cause disturbance in the cable arrangement, easy to damage cable ${ }^{[1]}$.

For this task, the test device has the advantages of small volume, buoyancy changes can be neglected, single drum winch scheme can make the inner tension cable design limit reached 80\%, the inner cable tension and the surface of the outer layer extrusion, long-term storage will seriously affect the cable service life and reliability. In the view of existing more than long cable winch design problems, proposed to use the double drum scheme, control retractable cable in constant state of tension, to solve the effect of cable for long-term storage of the service life and reliability. 


\section{Determine the Winch Design Scheme}

Dual winch system is mainly composed of a traction winch and storage winch ${ }^{[2]}$, a major role for the load recovery and release cable after storage in the storage Drum, winch used grooved storage drum structure, its size to ensure full recovery after order platoon clothed cable and have uniform stress. The traction tension measuring mechanism is arranged between the winch and the storage winch, the principle for the three wheels force ${ }^{[3]}$. By measure tension system to assurance the two winch before and after cannot interfere, the concrete structure of winch system as shown in figure 1 .

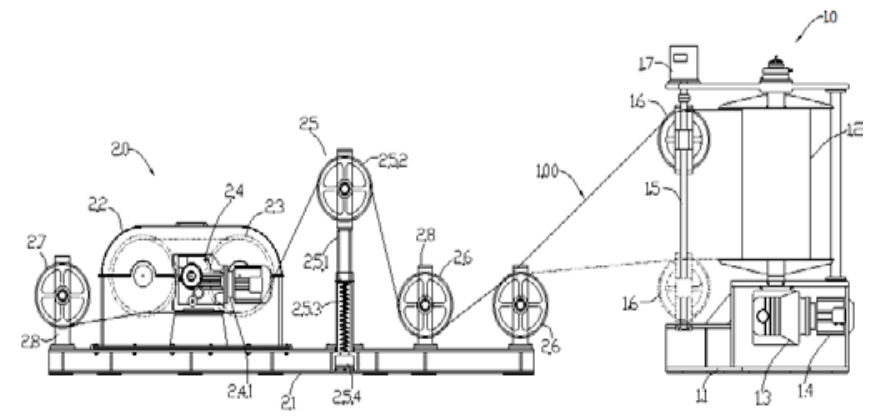

1.00-Cable, 1.0-Storage cable winch, 1.1-Storage winch base, 1.2-Storage drum, 1.3-Storage winch reducer, 1.4-Storage winch motor, 1.5-Fairleader screw, 1.6-fairleader, 1.7-Stepper motor, 2.0-The traction winch, 2.1-The traction winch base, 2.2-The traction winch gearbox, 2.3-Traction drum, 2.4-Towing winch gear, 2.4.1-Traction winch motor, 2.5 Tension Measurement System, 2.5.1-Stand, 2.5.2-Tension measuring wheel, 2.5.3-Buffer Spring, 2.5.4-Tension measurement sensors, 2.6-Guide wheel.

Figure 1 double drum winch deep-sea detection principle diagram

The traction winch by the same structure, the order of two winch constitution, $\mathrm{N}$ parallel with each winch cable trough. Connect the cable detector through a guide wheel into the traction winch, winch winding alternately on two drums, again through the guide wheel into the storage drum. Storage drum for single drum winch structure can accommodate all cable, axis along the vertical direction is arranged in the rear of the traction winch. Traction winch cable from the winch into the storage drum through the cable guide wheel and exhaust mechanism is wound on the spool. Cable which comprises a loading end into the traction winch, followed in the traction winch's two winch winding n-1 ring and two winch disc drive synchronization. By the friction of the cable trough and the cable produced lifting force. Due to the traction winch cable winding turns, cable tension is reduced ${ }^{[4]}$. Because of the traction winch "amplification" effect, storage winch need only to maintain a small tension, can meet the need to enhance the detector ${ }^{[1]}$. The concrete scheme is shown in figure 2.

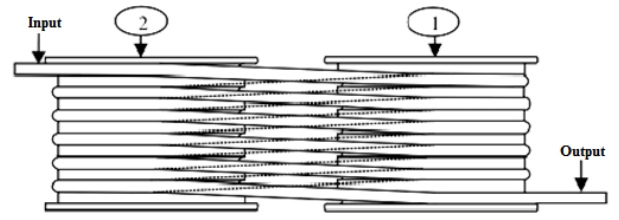

Figure 2 scheme of traction winch

The double drum traction winch is driven by a motor, the motor through reducer, connected with a gear box, the power is allocated to the double drum traction winch, guarantee double drum speed synchronous $^{[5]}$.

\section{Determination of main parameters of winch}

Winch specific design requirements is shown in table 1:

The specific design requirements in Table 1 winch

\begin{tabular}{|c|c|c|c|}
\hline Project & Goal & Project & Goal \\
\hline Loads weight & $200 \mathrm{~kg}$ & Cable diameter & $6.4 \mathrm{~mm}$ \\
\hline Cable weight & $500 \mathrm{~kg}$ & Drum diameter & $360 \mathrm{~mm}$ \\
\hline Drop speed & $0.5-0.75 \mathrm{~m} / \mathrm{s}$ & Cable length & $2000 \mathrm{~m}$ \\
\hline radius of curvature & $130 \mathrm{~mm}$ & temperature & $45^{\circ} \mathrm{C}$ \\
\hline
\end{tabular}


Because the detector system storage, acceleration and deceleration time is short, so only consider the system uniform retraction or static load end of the traction winch pull ${ }^{[6]}$.

$\mathrm{F}_{\mathrm{Z}}=\mathrm{G}_{\mathrm{T}}+\mathrm{B}_{\mathrm{L}} \mathrm{L}+\mathrm{D}_{\mathrm{Z}}-\mathrm{F}_{f}$

Where $G_{T}$ is the gravity probe $B_{L}$ cable; the gravity of unit length of cable length; $L$ release length; $\mathrm{D}_{\mathrm{Z}}$ is the $\mathrm{Z}$ force, relative to the detector system weight is small, it can be neglected; $\mathrm{F}_{\mathrm{f}}$ as a detector in the water buoyancy.

According to equation (1) in the work process, the maximum load occurs when cable fully release, so the traction winch lifting force must take $F_{Z}=6500 \mathrm{~N}$ to this load as the basis of design, safety coefficient, $\mathrm{K}=1.5, \mathrm{~F}_{\mathrm{ac}}=7800 \mathrm{~N}$.

In the process of retraction detectors, winch system provide lifting force. Traction winch and cable as a special transmission belt, as shown in Figure 3, can use Euler's formula to calculate the driving force of the traction winch. The cable is wounded on the windlass, winch rotates when the traction cable slip in the trend of the winch, the loose side force of $F_{2}$ winch each ring cable and tension side force $\mathrm{F}_{1}$ will have a difference $\Delta \mathrm{F}$, namely the capstan friction.

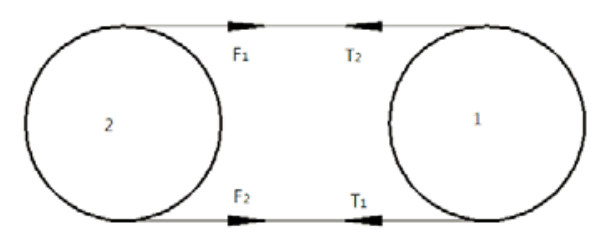

Figure 3 analysis chart of force traction winch

Design requires the detector to release speed of $0.5-0.75 \mathrm{~m} / \mathrm{s}$, therefore

$\frac{\mathrm{F}_{1}}{\mathrm{~F}_{2}}=\mathrm{e}^{\mu \alpha}$

Where $\mu$ is the friction coefficient between the cable and the drum and $\alpha$ is wrap angle of cable on the drum.

And $\Delta \mathrm{F}=\mathrm{F}_{1}\left(1-\mathrm{e}^{\mu \alpha}\right)$

From figure $3 \quad \mathrm{~F}_{1}^{\mathrm{i}}=\mathrm{T}_{2}^{\mathrm{i}}$

$\mathrm{F}_{2}^{\mathrm{i}}=\mathrm{T}_{1}^{\mathrm{i}+1}$

$\mathrm{F}_{1}^{\mathrm{i}}, \mathrm{F}_{2}^{\mathrm{i}}$ is tight side, slack side tension of Winch 2 .

$\mathrm{T}_{1}^{\mathrm{i}}, \mathrm{T}_{2}^{\mathrm{i}}$ is tight side, slack side tension of Winch 1 .

Above that $\mathrm{T}_{1}^{\mathrm{i}}=\mathrm{F}_{\mathrm{Z}}$.

By the above formula indicates:

The cable force on the winch 1

$\Sigma \Delta \mathrm{T}=\Sigma_{1}^{5}\left(\mathrm{~T}_{1}^{\mathrm{i}}-\mathrm{T}_{2}^{\mathrm{i}}\right)=\mathrm{F}_{\mathrm{Z}}\left(1-\mathrm{e}^{-\mu \alpha}\right)\left(1+\mathrm{e}^{-2 \mu \alpha}+\mathrm{e}^{-4 \mu \alpha}+\mathrm{e}^{-6 \mu \alpha}+\mathrm{e}^{-8 \mu \alpha}\right)$

The cable force on the winch 2

$\Sigma \Delta \mathrm{F}=\Sigma_{2}^{6}\left(\mathrm{~F}_{1}^{\mathrm{i}}-\mathrm{F}_{2}^{\mathrm{i}}\right)=\mathrm{F}_{\mathrm{Z}}\left(1-\mathrm{e}^{-\mu \alpha}\right) \mathrm{e}^{-\mu \alpha}\left(1+\mathrm{e}^{-2 \mu \alpha}+\mathrm{e}^{-4 \mu \alpha}+\mathrm{e}^{-6 \mu \alpha}+\mathrm{e}^{-8 \mu \alpha}\right)$

Therefore the cable force on the traction winch is

$\Sigma \Delta \mathrm{T}+\Sigma \Delta \mathrm{F}$

Then the tension of cable

$\mathrm{F}_{\mathrm{C}}=\mathrm{F}_{\mathrm{Z}}-\Sigma \Delta \mathrm{T}-\Sigma \Delta \mathrm{F}=\mathrm{F}_{\mathrm{Z}} \mathrm{e}^{-10 \mu \alpha}$

We can see from Figure 3 above a variety of wrap angle $\alpha=\pi$, the friction coefficient $\mu$ is 0.1 , in order to ensure the cable does not appear in the traction winch sliding phenomenon of $\mathrm{F}_{\mathrm{C}}$ must be greater than $\mathrm{F}_{\mathrm{Z}} \mathrm{e}^{-10 \mu \alpha}, \mathrm{F}_{\mathrm{C}}>281 \mathrm{~N}$.

For each traction winch, winch maximum traction torque is as follows:

The maximum torque of winch 1

$$
\begin{gathered}
\mathrm{M}_{1}=\mathrm{F}_{\mathrm{ac}} \mathrm{R}_{\mathrm{Q}}\left(1-\mathrm{e}^{-\mu \alpha}\right)\left(1+\mathrm{e}^{-2 \mu \alpha}+\mathrm{e}^{-4 \mu \alpha}+\mathrm{e}^{-6 \mu \alpha}+\mathrm{e}^{-8 \mu \alpha}\right)+\frac{\mathrm{J}_{0} \mathrm{v}}{\mathrm{R}_{\mathrm{Q}}} \\
=797.2 \mathrm{~N} \cdot \mathrm{m}
\end{gathered}
$$

The maximum torque of winch 2

$$
\begin{gathered}
\mathrm{M}_{2}=\mathrm{F}_{\mathrm{ac}} \mathrm{R}_{\mathrm{Q}} \mathrm{e}^{-\mu \alpha}\left(1-\mathrm{e}^{-\mu \alpha}\right)\left(1+\mathrm{e}^{-2 \mu \alpha}+\mathrm{e}^{-4 \mu \alpha}+\mathrm{e}^{-6 \mu \alpha}+\mathrm{e}^{-8 \mu \alpha}\right)+\frac{\mathrm{J}_{0} \mathrm{v}}{\mathrm{R}_{\mathrm{Q}}} \\
=587.3 \mathrm{~N} \cdot \mathrm{m}
\end{gathered}
$$


Total efficiency of gear box $\eta_{\mathrm{t}}=0.94$, so driving winch minimum input torque is:

$\mathrm{M}=\frac{\mathrm{M}_{1}+\mathrm{M}_{2}}{\eta_{t}}=1473 \mathrm{~N} \cdot \mathrm{m}$

The driving power for the winch 1 and winch 2 is analyzed as follows:

The drive power of winch 1

$$
\begin{aligned}
\mathrm{P}_{1}=\mathrm{F}_{\mathrm{ac}}\left(1-\mathrm{e}^{-\mu \alpha}\right)\left(1+\mathrm{e}^{-2 \mu \alpha}+\mathrm{e}^{-4 \mu \alpha}\right. & \left.+\mathrm{e}^{-6 \mu \alpha}+\mathrm{e}^{-8 \mu \alpha}\right)+\frac{\mathrm{J}_{0} \mathrm{v}^{2}}{\mathrm{R}_{\mathrm{Q}}} \\
& =4337 \mathrm{~W}
\end{aligned}
$$

The drive power of winch 2

$$
\begin{gathered}
\mathrm{P}_{2}=\mathrm{F}_{\mathrm{ac}} \mathrm{e}^{-\mu \alpha}\left(1-\mathrm{e}^{-\mu \alpha}\right)\left(1+\mathrm{e}^{-2 \mu \alpha}+\mathrm{e}^{-4 \mu \alpha}+\mathrm{e}^{-6 \mu \alpha}+\mathrm{e}^{-8 \mu \alpha}\right)+\frac{\mathrm{J}_{0} \mathrm{~V}^{2}}{\mathrm{R}_{\mathrm{Q}}} \\
=3171 \mathrm{~W}
\end{gathered}
$$

The output power of the drum is $\mathrm{P}=\mathrm{P}_{1}+\mathrm{P}_{2}=7508 \mathrm{~W}$

So the output power of motor

$\mathrm{P}_{\mathrm{d}}=\frac{\mathrm{P}}{\eta_{t}}$

$\eta_{t}=\eta_{1}^{2} \cdot \eta_{2} \cdot \eta_{3}^{2}$

Type $\eta_{1}$ for the rolling bearing transmission efficiency; $\eta_{2}$ worm reducer; transmission efficiency; $\eta_{3}$ coupling transmission efficiency.

To obtain the $\eta_{\mathrm{t}}=0.52$, so

$\mathrm{P}_{\mathrm{d}}=\frac{\mathrm{P}}{\eta_{t}}=14.42 \mathrm{~kW}$

Rated power of motor selectionP $\mathrm{ed}_{\mathrm{e}}=15 \mathrm{~kW}$.

Because of working on a ship, according to the rated power of the motor and the driving role torque required to select Y-H series marine motor, model is Y180L-6-H, the speed of $1400 \mathrm{r} / \mathrm{min}$.

In the process of detection system release and recovery are the need for strict ${ }^{[7]}$ speed control, especially during the release phase, the detecting system and the cable's self-weight may cause the motor reverse ${ }^{[8]}$, therefore need to select reducer ${ }^{[9]}$ with self-locking function. According to the transmission ratio and transmission torque selects CWU series turbine worm reducer, according to the input power selection center distance of 200, type CWU-200-40-I. The speed reducer has the characteristics of the whole body, modular design, mainly used for transmission of mechanical transmission two crossed axis motion and power, can effectively save space, also has the self-locking function under certain conditions.

\section{Control system}

\section{Tension measurement principle.}

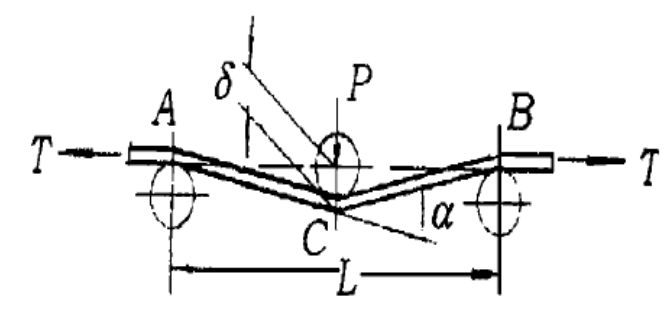

Figure 4 three tension measurement system works

Figure 4 is the three-point bending cable tension measurement mechanism of local deformation, under the effect of the tension $\mathrm{T}$, $\mathrm{C}$ with respect to the point $\mathrm{A}, \mathrm{B}$ points upward pressing, a displacement signal $\delta$ and the pressure signal $\mathrm{P}$, the figure shows that the center line of the cable declination $\alpha$, the system used in the cable of smaller diameter, which is considered fully flexible cable, there are:

$\mathrm{P}=2 \mathrm{~T} \sin (\alpha / 2)$ 


\section{Derivation of tension measuring formula.}

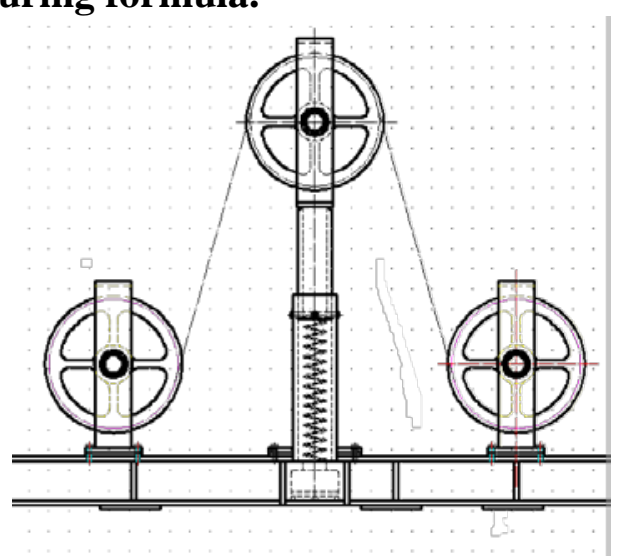

Figure 5 three tension measurement system diagram

Figure 5 shows that tension measurement system includes tension measuring wheel, creasing wheels, springs and sensors constitute compensation mechanism. Tension measuring wheel is located in the middle of two pressure line wheels, two wheels in the same horizontal pressure line, cable left after passing through the bottom side of the pressure line wheels. From the measurements above the wheel to get around, and then through the pressure line from the right side of the wheel for the formation of the center line of the deflection angle.

According to the geometric relationship between the cable tension suffered $\mathrm{T}$ and pressure sensor's pressure signal $P$ received is,

$$
T=\frac{P}{2 \sin \left(\arctan \frac{H-P / k}{L}\right)}
$$

The range between the towing and storage winches, winch cable tension $\mathrm{T}$ is

$380 N \leq T \leq 2000 N$

According to the system's design requirements, select the cable tension value of $\mathrm{T}$ for $500 \mathrm{~N}$.

By formula 10 shows that the calculation of the cable tension $\mathrm{T}$ needs to determine compensation device spring stiffness $\mathrm{k}$, compensation device and spring stroke $400 \mathrm{~mm}$.

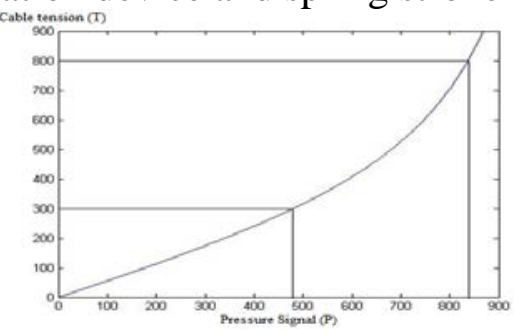

Figure 6 cable tension and pressure signal relationship

Figure 6 shows the relationship between the towing and storage winches winch cable tension and tension measuring mechanism between the measured pressure signals, the system is to set tension $500 \mathrm{~N}$. Allowing the tension instantaneous change in the system is running in the range of $300 \mathrm{~N}-800 \mathrm{~N}$, the pressure signal variation range is $480 \mathrm{~N}-830 \mathrm{~N}$.

\section{Simulation Control System}

In the double drum winch system, deep-sea exploration, the transfer function of the system can be approximated as

$$
G(S)=\frac{20}{S^{2}+3 S+5} e^{-2 s}
$$

\section{PID Fuzzy self-tuning control.}

PID Self-tuning fuzzy control system design simulation, first determine the domain were $\mathrm{E}$ $(-0.5,1)$, EC (-0.8,0.5), $K_{P}(-0.02,0.01), K_{I}(-0.02,0.04), K_{D}(-0.008,0.004)$, scale factor $G_{E}, G_{E C}$ and 
quantitative factors $G_{\mathrm{P}}, \mathrm{GK}_{\mathrm{I}}, \mathrm{GK}_{\mathrm{D}}$ were taken 1, the system output waveform is shown in Figure 7, self-tuning PID controller parameters $\mathrm{K}_{\mathrm{P}}, \mathrm{K}_{\mathrm{I}}, \mathrm{K}_{\mathrm{D}}$ over time t curve shown in Figure 8.

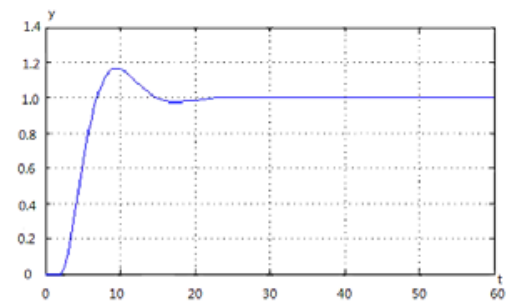

Figure 7 the unit step response of the system output waveform
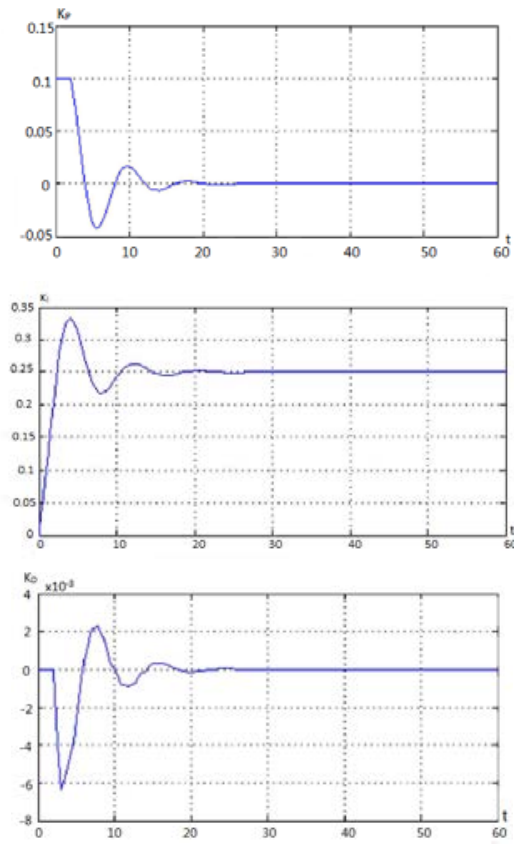

(a)KP Time curve (b)KI Time curve(c) KD The curve changes with time Figure 8 PID control parameters with the time change curve

\section{Fuzzy-PID with control parameter.}

According to the method of setting Ziegler-Nichols parameters, when the input signal for $5, \gamma=5$, Tuning fuzzy control module quantitative factors GE=0.05、GEC=0.22;PID parameters.

$$
\begin{gathered}
K_{P}=K_{P 0}-0.01 \gamma=[-0.07,-0.04] \\
K_{I}=K_{I 0}-0.01 \gamma=[-0.07,-0.01] \\
K_{D}=K_{D 0}+0.05 \gamma=[0.017,0.029]
\end{gathered}
$$

The response curve of the system is shown in Figure 9.

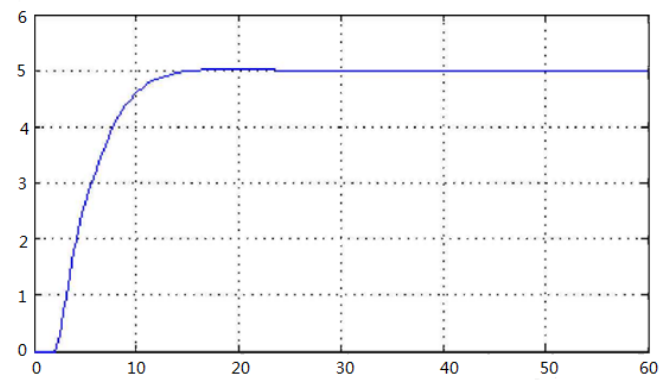

Figure 9 step 5 system response curve

The simulation study of fuzzy control system -PID get the system in the control process step signal response curve, through the analysis of simulation results can be learned, -PID fuzzy control system can satisfy the system control requirements. 


\section{Conclusion}

For this task, single drum winch scheme can make the inner tension cable design limit reached $80 \%$. The inner cable tension and the surface of the outer layer extrusion, long-term storage will seriously affect the cable service life and reliability. Aiming at the existing problems in the design of long-term winch, proposed to use the scheme of double drum, make the cable hoisting release process isolate with cable storage. Design the structure of winch and put it into the deep-water equipment, set up the transmission and control system of traction winch through design calculation, ensure the cable in the constant tension condition during the process of reeling. The tension is less than the limit by cable tension, reduce the tension, tension changes in the internal and external layer of the cable and service life and reliability which is affected by long-term storage of cable.

\section{Acknowledgment}

This research is sponsored by People's Republic of China National Science and Technology Major Project (2011ZX05056-003).

\section{References}

[1] Chen Yuxi, Zhang Zhuying. Deep sea ROV umbilical winch design of [J]. Mechanical design and manufacturing. In 2010 (04): 39-41

[2] Zhai Qingguang, Nie Jie, Kang Yue. Analysis of [J]. Ocean technology.2008 separation technique system of deep-sea investigation winch cable traction mechanism and storage mechanism (04): 8-12

[3] Zhai Qingguang, Nie Jie, Kang Yue. Reel cable tension analysis of [J]. Ocean technology.2008 deep-sea winch traction (02): 28-30

[4] Su Ningning, Li Huailiang, Duan Menglan, Mao Dong Feng, Zhao Tian Feng, Zhang Duan. Calculation and finite element strength analysis of [J]. Oil field equipment 2011 traction winch drum deep-water A\&R power, 40 (10): 45-49

[5] M.A.Vaz. Three dimensional transient analysis of the installation of marine cables. Acta Mechanio, 1997, 124:1-26

[6] Yao Ping, Longjiang Zhi. A design scheme of [J]. ROV mining vehicle in deep ocean mining machinery. 2006 (05): 18-21

[7] Chen Xiaoxing, Zhao Jinyuan, Wang Cheng. Study on [J]. Machine and hydraulic.2012 control based on disturbance observer marine winch speed (09): 7-11

[8] Feng Gang, Li Jianzhong, Tan Jia. Winch drive control system of [J]. Modular machine tool \& automatic processing technology of.2001 for the marine environment (06): 6-9

[9] Yang Fangqiong, Tan Qing, Peng Gaoming. Accurate positioning of deep-sea mining ROV long baseline system based on [J]. Ocean engineering. 2006 (03): 32-35 